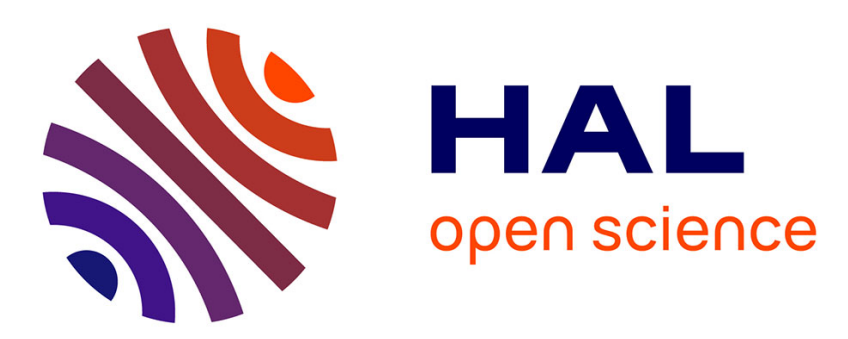

\title{
Schumpeterian Competition, Technological Regimes and Learning through Knowledge Spillover
}

Klaus Wersching

\section{To cite this version:}

Klaus Wersching. Schumpeterian Competition, Technological Regimes and Learning through Knowledge Spillover. Journal of Economic Behavior and Organization, 2010, 75 (3), pp.482. 10.1016/j.jebo.2010.05.005 . hal-00849408

\section{HAL Id: hal-00849408 https://hal.science/hal-00849408}

Submitted on 31 Jul 2013

HAL is a multi-disciplinary open access archive for the deposit and dissemination of scientific research documents, whether they are published or not. The documents may come from teaching and research institutions in France or abroad, or from public or private research centers.
L'archive ouverte pluridisciplinaire HAL, est destinée au dépôt et à la diffusion de documents scientifiques de niveau recherche, publiés ou non, émanant des établissements d'enseignement et de recherche français ou étrangers, des laboratoires publics ou privés. 


\section{Accepted Manuscript}

Title: Schumpeterian Competition, Technological Regimes and Learning through Knowledge Spillover

Author: Klaus Wersching

PII: $\quad$ S0167-2681(10)00087-9

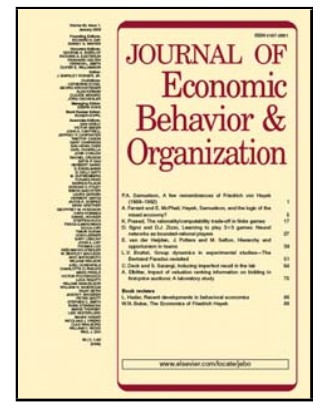

DOI: $\quad$ doi:10.1016/j.jebo.2010.05.005

Reference: $\quad$ JEBO 2540

To appear in: Journal of Economic Behavior \& Organization

Received date: $\quad 19-9-2007$

Revised date: $\quad 9-5-2010$

Accepted date: $\quad 16-5-2010$

Please cite this article as: Wersching, K., Schumpeterian Competition, Technological Regimes and Learning through Knowledge Spillover, Journal of Economic Behavior and Organization (2008), doi:10.1016/j.jebo.2010.05.005

This is a PDF file of an unedited manuscript that has been accepted for publication. As a service to our customers we are providing this early version of the manuscript. The manuscript will undergo copyediting, typesetting, and review of the resulting proof before it is published in its final form. Please note that during the production process errors may be discovered which could affect the content, and all legal disclaimers that apply to the journal pertain. 


\title{
Schumpeterian Competition, Technological Regimes and Learning through Knowledge Spillover*
}

\author{
Klaus Wersching ${ }^{\dagger}$
}

May 2, 2010

\begin{abstract}
This paper builds upon Winter (1984) in which the author discusses two views of Schumpeter on competition. Specifically, technological regimes and the role of knowledge spillovers for innovation are examined. An agent-based simulation model is formulated which captures the relevant aspect of competition between firms in an innovative industry. Results of the simulation runs indicate that at first, the technological development in terms of process and product innovations is better in an industry that is characterized by Schumpeter Mark II conditions. But the improved technological development is connected with higher prices and profits, which could be interpreted as a trade-off between static and dynamic efficiency. Second, in both scenarios market and industry concentration rises over time, showing a strong separation between successful firms and those lagging behind in technological terms. And third, surprisingly firms in a Schumpeter Mark I regime seem to be more technologically specialized. Furthermore, this article proves that a replication of simulation models is possible and useful.
\end{abstract}

Keywords: Innovation, Technological Regimes, Knowledge Spillover, Agent-based Simulation, Industry Dynamics

JEL Classification: D83, L1, O31, O33

\footnotetext{
*I would like to thank Bart Verspagen, Herbert Dawid, Jasmina Kitanovic and two anonymous reviewers for comments and advice. Financial support for this work was provided by the German Academic Exchange Service (DAAD).

${ }^{\dagger}$ BIELEFELD UNIVERSITY, Department of Business Administration and Economics, P.O. Box 1001 31, D-33501 Bielefeld, Germany, klaus.wersching@googlemail.com
} 


\section{Introduction}

One of the main questions raised by Schumpeter is what kind of market characteristics and technological environment promote innovations? The arguments proposed by Schumpeter do not give a clear answer. In his earlier writings the author admired small entrepreneurial firms which achieve profits from their mostly radical innovations (Schumpeter, 1912). Later on he thought that large monopolistic firms had better capabilities to push the technological frontier in small but numerous steps, which results in better technological development of an industry (Schumpeter, 1942).

The aim of this paper is to contribute to this discussion in order to get a better understanding of industrial dynamics connected with the technological development of an industry. From a policy perspective it could be of great importance to know what circumstances lead to more innovations because innovations seem to be the main source of economic growth. Knowing the mechanisms at work would allow policy makers to create appropriate measures supporting firms and public institutions.

Therefore research questions which are approached in this work are: Which view of Schumpeter is right; what surrounding leads to a better technological development of an industry? What is the effect of competition in an innovative industry; is there a clear relation between market structure and innovation? And last, what is the role of knowledge spillovers; how does internal and external learning influence the technological development?

In the seminal work of Nelson and Winter (1982) it was shown that building simulation models may be one way to add value to this kind of research questions. In Winter (1984) the author proposes to model and to discuss two stylized scenarios in order to get a clearer picture of the mechanisms described by Schumpeter: In the entrepreneurial regime firms rely more on external learning, the results of innovation are more stochastic, and there are many entries of innovative firms in the industry. In contrast to this, the routinized regime is characterized by firms concentrating on internal $R \& D$ (innovation and imitation) and by the fact that the outcome of innovations depends on old techniques previously used in the firm. As results of the simulation study Winter (1984) shows that in the entrepreneurial regime average productivity changes more smoothly; the industry is less concentrated and less profitable compared to the routinized regime. The evolution of prices is similar in both scenarios.

In a model by Dosi et al. (1995) the evolution of an industry is observed under different scenarios described by several features of technological regimes. Apart from the learning conditions, which are defined as stylized archetypes called Schumpeter Mark I and Schumpeter Mark II (and an intermediate regime), the model considers birth and death of firms as well as life cycle patterns on the demand side. The model is used to explain characteristics of industrial structures by alternative regime parameters. The authors conclude that it was possible to reproduce a rich set of stylized facts. One drawback of the paper could be seen in the fact that the focus is more on showing correlations between aggregated properties and system parameters than on formulating behavior assumptions, which could be seen as major causes for the emerging regularities. Another work by Llerena and Oltra (2002) concentrates on the aspect of learning and the diversity of innovation strategies in an industrial dynamics setup. One learning strategy is understood as internal learning-by-searching of cumulative firms. Contrary to this non-cumulative firms adopt an external learning strategy that aims at absorbing external sources of knowledge. Apart from configurations, which consider a pure cumulative respectively non-cumulative case, a third configuration describes the outcome when firms with different learning strategies interact. As a result the diversity in the last scenario shows the best technological performance. Here a pattern emerges where few surviving cumulative firms with high market shares generate high spillovers to a 
fringe of small non-cumulative firms. And finally Garavaglia et al. (2006) formulate a history-friendly model of the pharmaceutical industry, in which a differentiation between the two technological regimes was also taken into account.

The proposed model elaborated in this paper tries to combine elements of the previously addressed models and is formulated as an agent-based simulation model. According to Tesfatsion (2006) an agent-based simulation model allows a "computational study of economic processes modeled as dynamic systems of interacting agents". ${ }^{1}$ Agents are understood as heterogeneous firms and consumers with heterogeneous preferences in an evolving industry. Firms act via routines embedded in their institutional framework, and market interaction is represented as a single period equilibrium system in tradition of evolutionary modeling (see Nelson and Winter, 1982). Different to previous work this model describes the firms' interaction on several product markets defined by different technologies. Firms compete at the same time in their strategies to introduce new products and to reduce production cost through process innovations. Additionally the role of knowledge and knowledge spillover is highlighted in the model. This allows a representation and discussion of learning effects in different technological regime. Main findings of the paper indicate that there are structural differences in the interpretation and the outcome of alternative technological regimes. No type of technological regimes seems to dominate the other because each is connected with advantages and disadvantages from a political point of view.

Further, this paper is interesting from a methodological point of view because the outcome of our model is compared to the results of a previous simulation model, namely Winter (1984). Several scholars stress this topic in the literature under the notions of docking (the alignment of computational models, see Burton, 2003) and replication (the reproduction of earlier results, see Hamermesh, 2007; Windrum et al., 2007). This process is in particular important for simulation models. As Hales et al. (2003) argue a result from simulations is more reliable if it is reproduced many times by different modelers and re-implemented on several platforms in different places. In this article we reproduce most of the outcome of Winter (1984) in a different model which supports the earlier findings. Furthermore, we also add new arguments to the debate in the context of product innovations, learning and firm specialization.

The remainder is organized as follows. The following section 2 introduces the definition of a technological regime and sums up the debate in the literature. After that section 3 explains how the aspects of technological regimes can be represented in a simulation model. The main results of the simulation study are given in section 4 . The paper closes with the conclusions where further research issues and limitations of this approach are discussed.

\section{Technological Regimes and Competition}

The debate on technological regimes can be tracked back to the writings of Schumpeter, where the author described rather different constellations of competition and the role of innovations. In Schumpeter (1912) the author emphasized the role of small entrants who challenge the incumbents with their innovations. In the literature this scenario was named as Schumpeter Mark I. ${ }^{2}$ In his later days Schumpeter (1942) almost radically changed his view to the effect that now for him large firms had

\footnotetext{
${ }^{1}$ An overview of agent-based simulation models focusing on innovation and the technological development of an industry is presented in Dawid (2006).

${ }^{2}$ The labels Schumpeter Mark I and Schumpeter Mark II were first used by Nelson and Winter (1982) and Kamien and Schwartz (1982).
} 
better capabilities to accumulate knowledge and gain economic profits from innovations. This view was labeled as Schumpeter Mark II. In order to characterize fundamental differences in the structure of innovative conditions the notion of technological regimes was introduced. Technological regimes are defined by Nelson and Winter (1982) as the technological environment of an industry under which firms operate.

Malerba and Orsenigo $(1996,2000)$ have proposed that a technological regime can be seen as a certain combination of the following properties of technologies: opportunity conditions, cumulativeness conditions, appropriability conditions and knowledge base. Opportunity conditions reflect the abundance of knowledge external to an industry. They express how easily a firm can successfully perform an innovation with a given amount of resources invested in search. Cumulativeness conditions define to what extent the build-up of new knowledge depends upon the knowledge already accumulated in the firm. The appropriability conditions stand for the ease of extracting profits from innovation and the protection of intellectual property rights. The possibilities of imitation have a great influence on the level of appropriability. As a last characteristic the knowledge base specifies the key dimensions of knowledge relevant for innovation activities.

The nature of learning is important for innovations and can be described by the properties of technological regimes, too. Learning in this paper is understood as knowledge transfer which can occur from institutions external to the industry to firms, or between firms and within firms of an industry. If firms have possibilities to learn from public institutions, e.g. universities, it could be argued that opportunity conditions are high. The cumulativeness condition on the other hand is significant for learning within a firm. It represents the way firms can build up knowledge and how knowledge of a related technology can be transferred. These activities should represent internal knowledge spillovers. On the other hand, the appropriability conditions and the type of knowledge base are of major importance for external knowledge spillovers which are knowledge flows between firms. If knowledge circulates very easily between competitors and cannot be protected by legal authorities, the appropriability conditions of innovations are low. The degree of tacitness of knowledge, which is given by the characteristics of the knowledge base, and aspects of proximity ${ }^{3}$ are important for the transfer of knowledge. Altogether we see that learning is strongly connected to technological regimes.

When it comes to the debate of market structure and innovation, the ease of innovative entry in an industry is the first relevant aspect. Technological entry barriers define the competitive advantages of the incumbents over potential competitors related to knowledge and innovations (see Pavitt et al., 1989; Marsili, 2001). A highly cumulative character of knowledge, low knowledge spillover between firms and no learning from public sources may result in high technological entry barriers and prevent firms from entering a market. The question whether competition increases or decreases firms' incentive to innovate, is the second aspect of market structure and innovation. After Schumpeter (1942) it was assumed that innovation would decline with competition as more competition reduces the monopoly rents that reward successful innovators. Taking this relation as true it could be argued that there is a trade-off between static and dynamic efficiency, because more innovations would occur in more concentrated industries. Empirical studies to this topic do in general not support this view. For example a recent article indicates a complex nonlinear function in the form of an inverted u-shape (Aghion et al., 2005). In contrast to this Nelson and Winter (1982) argue that both variables, market structure and innovations, are endogenous to the nature of a technological regime so that the discussion on competition and innovation had better taken into account the fundamental properties

\footnotetext{
${ }^{3}$ Among other Boschma (2005) emphasises the role of technological and geographical proximity for knowledge spillover.
} 
of technological regimes (Marsili and Verspagen, 2002). ${ }^{4}$

Beside the theoretical debate on technological regimes, empirical works try to indicate regularities which characterize certain properties of technological regimes in different industries (see e.g. Pavitt, 1984; Pavitt et al., 1989; Audretsch, 1991; Malerba and Orsenigo, 1996; Breschi et al., 2000; Marsili, 2001; Marsili and Verspagen, 2002). For example Malerba and Orsenigo (1996) study six countries (D, F, GB, I, USA, J) and 49 technology classes. They find evidence that 19 technological classes (including mechanical technologies and traditional sectors) indicate patterns of Schumpeter Mark I and 15 technological classes (including chemicals and electronics) could have been characterized as Schumpeter Mark II. The results within each technology class have been remarkably similar across all countries.

\section{The Model}

In order to compare the two scenarios with different technological regimes this section introduces an agent-based simulation model. This paper builds on previous simulation work by Dawid and Reimann (2005, 2010) and Wersching (2007). The dynamic perspective of the simulation model enables the analysis of the technological development of a horizontally differentiated industry. Knowledge is seen as the major factor driving the technological development. Firms can use knowledge for process and product innovations. Another merit of the model is that it allows an analytical description of the learning processes through knowledge spillover between and within firms. The next paragraphs summarize the main structure of the model and concentrate on the aspects relevant for the representation of technological regimes.

\subsection{Formulation of the Model}

An important feature of the model is that we incorporate the accumulation of a structured stock of knowledge of each individual firm $i=1 . . n$. Due to investments for process and product innovation and to technological spillovers, firms build up technology-specific stocks of knowledge for each of the product variants $j=1 . . m_{t}$ they are currently producing or plan to introduce to the market in the future.

The build-up of a knowledge stock for innovations has the property that it is a time consuming process where experiments and knowledge is step by step accumulated over time indicated by period $t$. It is also assumed, that the return to investment, measured by increases in the knowledge stock, decreases as the company approaches the technological frontier. The same mechanisms hold for both types: the knowledge stocks for product innovations $R D_{i, j, t}^{\text {prod }}$ and the knowledge stocks for process innovations $R D_{i, j, t}^{\text {proc }}$. For example the knowledge stock for process innovations depends on own investments in $\mathrm{R} \& \mathrm{D}\left(I_{i, j, t-1}^{\text {proc }}\right)$ and spillovers $^{5}\left(S P_{i, j, t}^{\text {proc }}+S P_{i, j, t}^{e x t}\right)$, whereas $\alpha_{i}$ and $\beta_{i}$ are firm specific parameters:

$$
R D_{i, j, t}^{\text {proc }}=1-\left(1-R D_{i, j, t-1}^{\text {proc }}\right) \frac{1+\alpha_{i} \beta_{i}\left(I_{i, j, t-1}^{\text {proc }}+S P_{i, j, t}^{\text {proc }}+S P_{i, j, t}^{e x t}\right)}{1+\alpha_{i}\left(I_{i, j, t-1}^{\text {proc }}+S P_{i, j, t}^{\text {proc }}+S P_{i, j, t}^{e x t}\right)}
$$

The knowledge buildup process in the external institution (only in the Schumpeter Mark I scenario) works similar to the knowledge accumulation of the firms. The knowledge stock $R D_{j, t}^{\text {ext }}$ is increased

\footnotetext{
${ }^{4}$ See also Cohen (1995) in this context.

${ }^{5}$ To be more precise there are three forms of knowledge spillovers: spillovers within a firm, spillovers between firms and spillovers from the external institution to the firm.
} 
by public investments $I_{j, t-1}^{e x t}$ analogously to equation (1):

$$
R D_{j, t}^{e x t}=1-\left(1-R D_{j, t-1}^{e x t}\right) \frac{1+\alpha^{e x t} \cdot \beta^{e x t} \cdot I_{j, t-1}^{e x t}}{1+\alpha^{e x t} \cdot I_{j, t-1}^{e x t}}
$$

The level of knowledge spillovers $S P_{i, j, t}^{\text {proc }}$ of firm $i$ and technology $j$ in $t$ is seen as hump-shaped relationship of the technological gap $t_{j l, t}$, which refers to the difference in the amount of (technologyspecific) knowledge that has been accumulated. The intensity of knowledge flows within the firm $\left(\omega_{i n}\right)$ and between firms $\left(\omega_{e x}\right)$ has an impact as well as the absorptive capacity $\gamma_{i, t}$, which is understood as the arithmetic mean over all knowledge stocks. The greater the technological distance $d_{j, l, t}^{t e c h}$ between the technologies, the lower is the outcome for learning.

$$
S P_{i, j, t}^{\text {proc }}=\underbrace{\omega_{i n} \sum_{l}\left[\frac{1}{1+d_{j, l, t}^{\text {tech }}} \cdot t_{j l, t} \cdot e^{-\frac{t_{j l, t}}{\gamma_{i, t}}}\right]}_{\text {internal Spillover }}+\underbrace{\omega_{e x} \sum_{l} \sum_{k \neq i}\left[\frac{1}{1+d_{j, l, t}^{\text {tech }}} \cdot t_{j l, t} \cdot e^{-\frac{t_{j l, t}}{\gamma_{i, t}}}\right]}_{\text {external Spillover }}
$$

Beyond the technological distance in the technology space the formula for knowledge spillovers given in equation (3) also considers own and other knowledge stocks which are part of the technological gap as well as the absorptive capacity. The relationship of the knowledge stocks on the resulting spillover is rather complex. In general learning increases if the knowledge gap takes medium values because very similar knowledge as well as great differences in the knowledge lower the learning possibilities, see e.g. Wuyts et al. (2005) for an empirical work supporting this assumption. The absorptive capacity influences knowledge spillovers in the way that the potential learning outcome rises with an increasing absorptive capacity. Obviously, these assumption are crucial for the transfer of knowledge. It should also be emphasized that the relevant variables for knowledge spillovers (knowledge stocks and technological distances) evolve endogenously in the model.

Firms (at least in the Schumpeter Mark I scenario) can use the public knowledge, but the knowledge spillovers from the external institution $S P_{i, j, t}^{e x t}$ again depend on the firms' capabilities to exploit knowledge analogously to equation (3):

$$
S P_{i, j, t}^{e x t}=\omega^{e x t} \sum_{l}\left[\frac{1}{1+d_{j, l, t}^{t e c h}} \cdot t_{j l, t} \cdot e^{-\frac{t_{j l, t}}{\gamma_{i, t}}}\right]
$$

Knowledge of firms can be used either for process or product innovations. Process innovations reduce production cost as the specific knowledge stock for a certain sub-market increases. The level of knowledge for process innovations for each technology corresponds with the production cost $c_{i, j, t}$ for variant $j$ of firm $i$ in $t$. Higher knowledge in a technology leads directly to lower production cost in the following way:

$$
c_{i, j, t}=c^{i n i}\left[c^{\text {min }}+\left(1-c^{\text {min }}\right)\left(1-R D_{i, j, t}^{\text {proc }}\right)\right]
$$

In contrast to process innovation a knowledge stock for product innovation $R D_{i, j, t}^{p r o d}$ greater than zero does not automatically lead to successful product innovation. In fact the immanent uncertainty with product innovations is captured by a stochastic process which determines every period whether a product innovation is successful or not. A product innovation can be either incremental or radical. Two numbers were chosen: $u$ from the uniformly distributed interval $[a, b]$ with $0<a<b$, and $v$ from the uniformly distributed interval $[b, c]$ with $b<c \leq 1$. If $R D_{i, j, t}^{\text {prod }}>u$ the firm $i$ was able to introduce a product innovation on the market. If $R D_{i, j, t}^{\text {prod }}>v$ the new product was a technological 
breakthrough, which could be interpreted as a radical innovation. Otherwise the product innovation is incremental. The initial $\mathrm{R} \& \mathrm{D}$ stock for a new product variant $R D_{j}^{0}$ is chosen according to the characteristics of the technological regimes, see table 1. After the successful introduction of a new product variant the knowledge stock in this particular field is erased.

Successful product innovations generate a new sub-market in the industry, which is located on the circular technological space between two existing technologies. However, the new technology creates a new market opportunity but this new technology does not make obsolete the knowledge of neighboring firms. If the product innovation is radical, the circular technological space expands, so there will be a new market which initially is far from its neighbors. Hence, the number of product variants, which is equal to the number of markets, is determined endogenously through product innovations.

After the founding of a new sub-market the innovating firm stays for $\tau$ periods monopolist on this market, what can be interpreted as a patent that prevents imitation of the new product variant. Thus, the parameter $\tau$ stands for the length of the patent protecting product innovations. After this period all other companies can enter the market and offer the same type of product. The entry decision ${ }^{6}$ depends on the profits of the incumbents and the own production abilities given by the knowledge for process innovation. For a successful market penetration not only the knowledge for process innovation of the considered market but also that of neighboring markets is relevant. Hence, the capabilities of the firm and the technological surrounding have an impact on the transfer of knowledge through learning. This constitutes a technological barrier to entry. On the other hand, firms can also exit markets, if they make negative profits. Therefore, although the total number of firms in the industry $n$ is assumed to stay constant, the number of firms who are active on a certain sub-market is determined endogenously.

The demand side of the model incorporates several horizontally differentiated product variants. Each product variant is characterized by a location on a one-dimensional circular technological space. To keep things simple it is assumed that product differentiation is entirely due to technological differences between products and, hence, product positioning is equivalent to technological positioning. The consumers are assumed to be uniformly distributed on the circular technological space and they prefer to buy product variants which are technological closest.

The technological distance between the technologies $j$ and $j+1$ at time $t=1 . . T$ should be $d_{j, j+1, t}^{t e c h}$. If all consumers have the budget $B_{m}$ the overall budget $B_{j, t}$ for each sub-market $j$ at $t$ can be calculated as:

$$
B_{j, t}=\left(d_{j, j+1, t}^{t e c h}+d_{j-1, j, t}^{t e c h}\right) \cdot B_{m} / 2
$$

On each sub-market several firms are active. As in Nelson and Winter (1982) the inverse demand function for market $j$ with budget $B_{j, t}$ and output $X_{j, t}=\sum_{i} x_{i, j, t}$ is given by:

$$
p_{j, t}=\frac{B_{j, t}}{X_{j, t}}
$$

The firms' behavior is based on decision rules in the tradition of evolutionary modeling (Nelson and Winter, 1982). Firms have different ways of evaluating sub-markets and locations. Depending on this evaluation they will invest in product and process innovations, enter or exit sub-markets. Each submarket is associated with a technology and hence the technological location is set either by market entry in a promising sub-market or by product innovation. For the evaluation of the sub-markets two aspects are taken into account: the technological distance to its neighbors and to the own main

\footnotetext{
${ }^{6}$ See also below for more details on the decision rules of the firms. The formalization is given in Wersching (2007).
} 
technological expertise. Quantity decisions are made based on the assumption that all competitors will adapt quantities by an identical factor. Given this assumption firms choose their output in order to maximize profits on every active sub-market. ${ }^{7}$

With derived output quantities $x_{i, j, t}$ the calculation of prices $p_{j, t}$ (see equation (7)) and profits $\Pi_{i, j, t}$ is possible (it also assumed that each firms has to bear fixed cost $F_{i}$ in order to be active on each sub-market $j$ ):

$$
\Pi_{i, j, t}=p_{j, t} \cdot x_{i, j, t}-c_{i, j, t} \cdot x_{i, j, t}^{2}-F_{i}
$$

$\mathrm{R} \& \mathrm{D}$ investments are calculated by the product of profits $\Pi_{i, t}$ with the corresponding firm specific parameters $q_{i}^{\text {prod }}$ and $q_{i}^{\text {proc }}$. Whereas investments in product innovations are only chosen in one technology $j$, the investments in process innovations can be spread over more technologies:

$$
\begin{aligned}
I_{i, j, t}^{\text {prod }} & =q_{i}^{\text {prod }} \cdot \sum_{j} \Pi_{i, j, t} \\
\sum_{j} I_{i, j, t}^{\text {proc }} & =q_{i}^{\text {proc }} \cdot \sum_{j} \Pi_{i, j, t}
\end{aligned}
$$

In conclusion the firms in this model compete in quantities of selected product variants over several periods. If they are successful, the earned profits can be invested in innovation activities. Innovations help to establish the market position by reducing production cost and by earning innovation rents of new product variants. The selection process works in the way, that less competitive firms produce fewer different types of products and even loose market shares on their active markets. How the two technological regimes can be explored in this setup and how they influence the industry outcome is assessed in the following section.

\subsection{Modeling Technological Regimes}

Building on the characteristics of the Schumpeter Mark I and Schumpeter Mark II scenarios mentioned in section 2, the representation in the model is summarized in table 1. If the parameters are indicated as an interval, the values for the parameters were chosen at start uniformly distributed in the given range for every simulation run.

In the Schumpeter Mark I or entrepreneurial regime the sources of knowledge are mainly external to the firm. Beside high knowledge spillovers from competitors firms learn from an institution which is understood to be external to the industry. The institution provides and extends knowledge in existing technologies and all firms can benefit from its technological advances. The amount of knowledge transfer from the institution to the firms depends on each firm's absorptive capacity. Examples of external institutions occur every time when researchers or firm representatives from other industries meet firm representatives from this specific industry, e.g. in universities, at think tanks, exhibitions or conferences. For simplicity it is assumed that the investments for the external institution are funded by public authorities. Imitation between companies is the second source of external learning. High opportunities for imitation and a short patent length result overall in low technological barriers to entry. Entry in new markets is possible after only one period and the high level of external knowledge

\footnotetext{
${ }^{7}$ For the objective of this paper the description of the firm strategies and output decisions of the firms are not in the main interest, because these strategies (given by parameters $\kappa_{i}$ and $\delta_{i}$ ) do not change in the different technological regimes. For a detailed discussion of the firm strategies and chosen representation in the model please refer to Wersching (2007).
} 


\begin{tabular}{c|c|c} 
& Schumpeter Mark I & Schumpeter Mark II \\
\hline \hline External Institution & $\begin{array}{c}\text { Yes } \\
\left(I_{j, t}^{e x t}=[1,2], \omega^{\text {ext }}=1\right)\end{array}$ & No \\
\hline Process Innovations & $\begin{array}{c}\text { Low Investments } \\
\left(q_{i}^{\text {proc }}=[0.02,0.04]\right)\end{array}$ & $\begin{array}{c}\text { High Investments } \\
\left(q_{i}^{\text {proc }}=[0.08,0.16]\right)\end{array}$ \\
\hline Product Innovations & $\begin{array}{c}\text { Easier and more radical } \\
(a=0.93, b=0.935, c=0.94)\end{array}$ & $\begin{array}{c}\text { Higher thresholds } \\
\text { and mostly incremental } \\
(a=0.935, b=0.94, c=0.95)\end{array}$ \\
\hline $\begin{array}{c}\text { Initial Knowledge } \\
\text { for new Technologies }\end{array}$ & $\begin{array}{c}\text { Non-Cumulative } \\
\left(R D_{j}^{0}=\left[R D^{0}, 0.5\right]\right)\end{array}$ & $\begin{array}{c}\text { Cumulative } \\
\left(R D_{i, j-1, t}^{\text {proc }}+R D_{i, j+1, t}^{\text {proc }}\right)\end{array}$ \\
\hline Patent Length & $\begin{array}{c}\text { Short Patent Protection } \\
(\tau=1)\end{array}$ & $\begin{array}{c}\text { Long Patent Protection } \\
(\tau=10)\end{array}$ \\
\hline Knowledge Spillover & $\begin{array}{c}\text { High external and } \\
\text { low internal Spillovers } \\
\left(\omega_{\text {ex }}=0.1, \omega_{i n}=0.1\right)\end{array}$ & $\begin{array}{c}\text { No external, but } \\
\text { high internal Spillovers } \\
\left(\omega_{e x}=0, \omega_{i n}=1\right)\end{array}$ \\
\hline $\begin{array}{c}\text { Number of Firms } \\
\text { in the Industry }\end{array}$ & $\begin{array}{c}\text { Many } \\
(n=10)\end{array}$ & $\begin{array}{c}\text { Few } \\
(n=5)\end{array}$ \\
\hline
\end{tabular}

Table 1: The representation of technological regimes in the model. (In brackets are the corresponding parameters.)

spillover allows fast catch-up to technological leaders in the sub-markets. The industrial environment is characterized as 'creative destruction' because the thresholds for incremental and radical product innovations are lower than in the other scenario. The industry is less concentrated because there are more firms in the industry and each sub-market is initialized as a duopoly so that every firm faces a direct competitor in their core market. Although the industry has a fixed number of firms the market structure on every sub-market is determined endogenously as firms can enter and exit markets.

The Schumpeter Mark II or routinized regime is in contrast characterized by large established firms. This fact is represented in the way that the industry consists of fewer firms which start as a monopolist on one sub-market. The main sources of knowledge are seen internal to the firm with high investments in process innovations and high knowledge spillover within the firm, where knowledge from one technology is used to gain new knowledge in another technology. There exists no public external institution. In the literature this scenario is described as 'creative accumulation'. The thresholds for product innovations are higher, so that on the average more knowledge is needed to achieve a product innovation. Altogether there are high technological barriers to entry in the Mark II scenario resulting from the long patent length and the absence of external learning. This fact is underlined by the cumulative structure of knowledge. A successful product innovation is initialized in the way that the starting level for process innovation depends on the knowledge of the innovating firm in neighboring technologies.

While comparing these two stylized scenarios it is important to note that other aspects are not varied in the two technological regimes. Among them are strategies, capabilities and resources of the firms as well as the technological space at start (which means that the technological specialization of firms and industry is equal, too) and the preferences of the consumers. Firm strategies stay constant but the technological space changes as the industry evolves. The settings of the fixed parameters can be found in Appendix A. 


\section{Comparing two stylized Technological Regimes}

In this section the model is analyzed with respect to technological development, main industry characteristics and learning through knowledge spillover. All graphs are based on 100 simulation runs in the described settings. In most cases the two stylized technological regimes are compared with the arithmetic mean over all runs. Apart from the graphical presentation the results are underlined with Wilcoxon rank sum tests. The outcome of the simulation studies, which is going to be discussed in the following part, appears to be highly significant. See Appendix B for more details.

\subsection{Technological Development of the Industry}

The first figure 1 displays the number of product variants over time in the two scenarios. In contrast to the model of Winter (1984) the number of sub-markets in the industry is not constant.

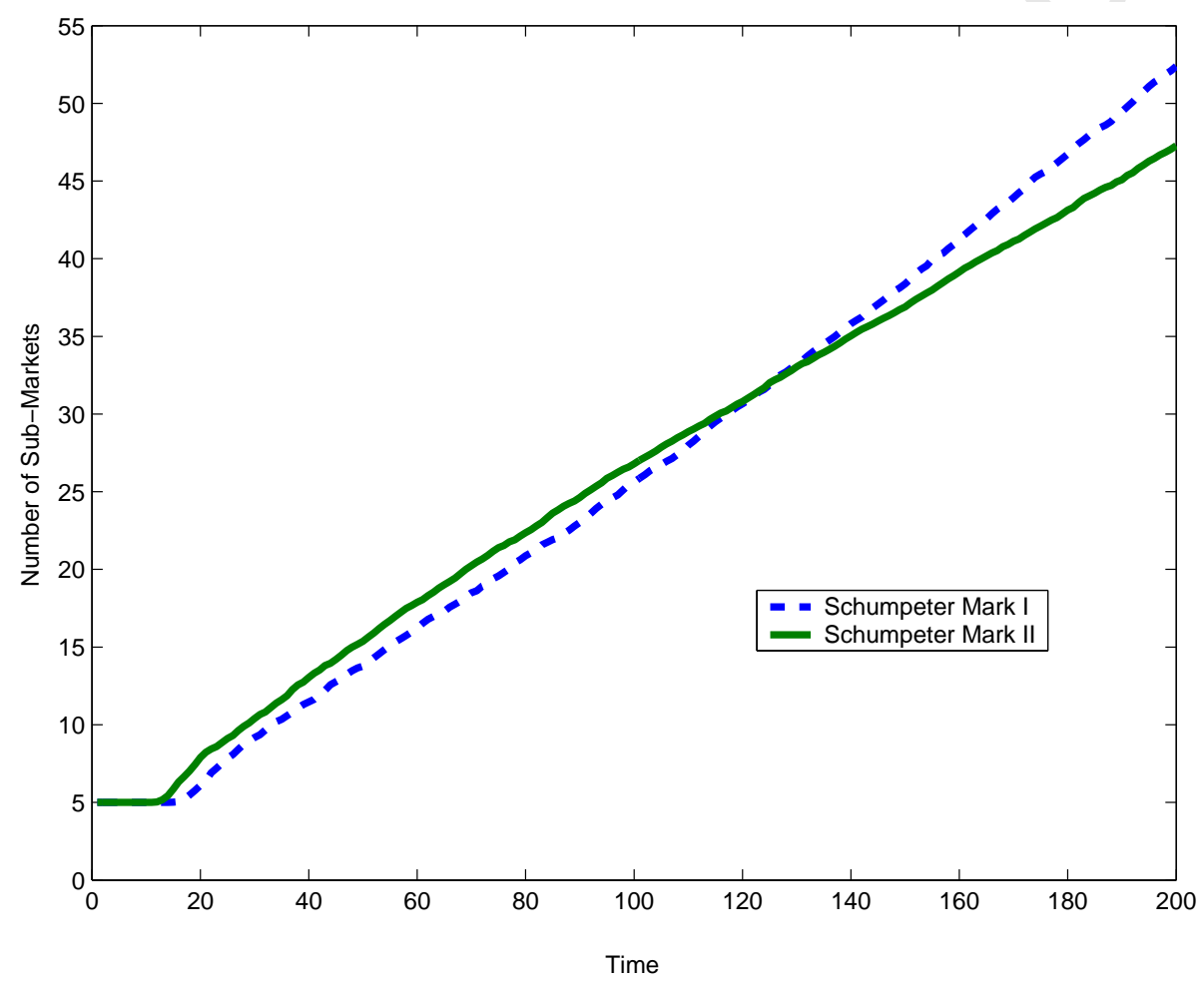

Figure 1: Average Number of Product Innovations.

The industry is initialized with 5 sub-markets and every additional variant represents a successful introduction of a new product. The results yield that the number of product innovations is quite similar for both types of technological regimes. But interesting is the fact that in the first half there are on the average earlier and more product innovation in Schumpeter Mark II whereas later on the number of markets is higher in Schumpeter Mark I. It can be shown that the difference is further increasing as the simulations continue. The thresholds for product innovations are first reached by firms in Schumpeter Mark II although more knowledge ${ }^{8}$ is necessary to introduce a new product variant. As the industry evolves, the number of product innovations is growing faster in Schumpeter Mark I.

Apart from the number of product innovations there exists a structural difference in the type of

\footnotetext{
${ }^{8}$ See parameters $a, b$ and $c$.
} 


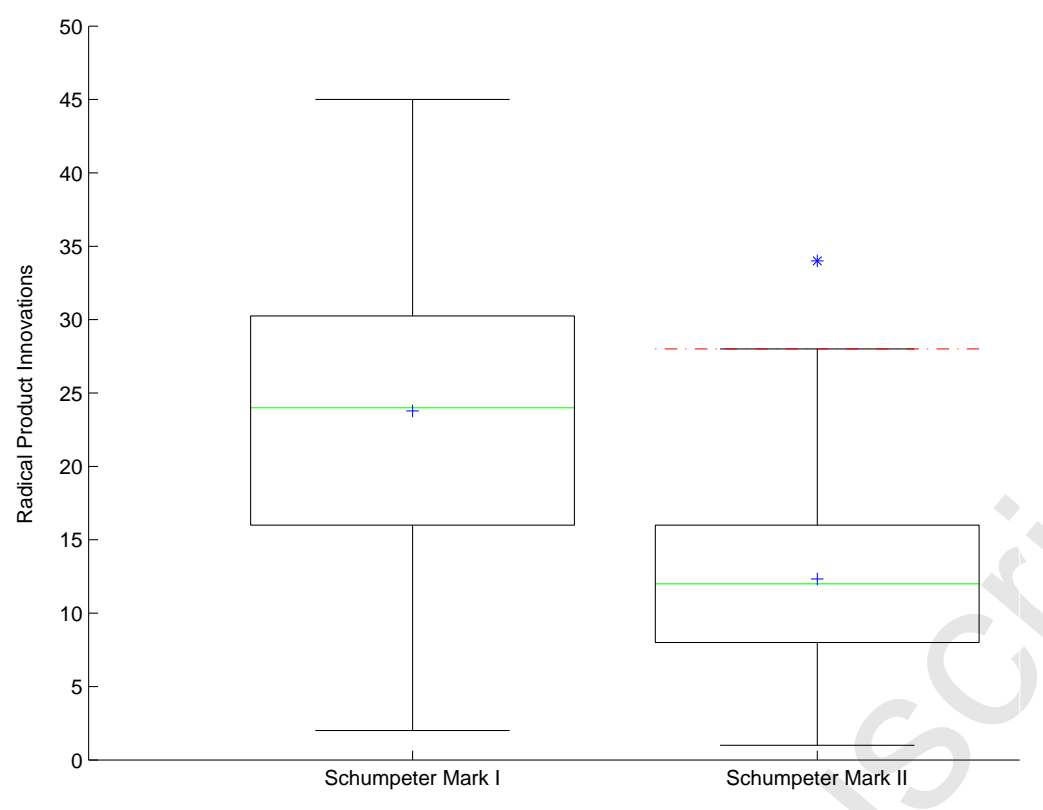

Figure 2: Boxplot of Radical Product Innovations at $\mathrm{T}=200$.

product innovations. In order to show this effect, figure 2 draws boxplots ${ }^{9}$ of successful radical product innovations till $T=200$ in the two technological regimes. The boxplot provides a quick idea of the distribution of the simulated data at a certain point in time. It depicts the smallest observation, lower quartile, median, upper quartile, and largest observation as well as outliers which are marked by a star.

The boxplot proves that there are far more radical product innovations in Schumpeter Mark I. This result is driven by the assumption that product innovations are easier and more radical in Schumpeter Mark I. Despite the similar number of product innovations the technological space changes in Schumpeter Mark I much more radically. Whereas in Schumpeter Mark II firms compete with more technologically close product variants with limited demand, firms in Schumpeter Mark I benefit from new consumers which are attracted to the industry through radical product innovations. There seems to be more competition between product variants than competition in sub-markets in Schumpeter Mark II.

Process innovations complete the picture of the technological development of the industry. Like Winter (1984) the scenarios are analyzed with best practice and average values for process innovations over all firms and sub-markets. Figure 3 captures the evolution of the first 100 periods on the level of best practice (a) and over 200 periods for the average productivity (b).

In all cases the industry starts at $R D^{0}=0.2$. The best practice for process innovations is rising fast in Schumpeter Mark II. Firms in Schumpeter Mark I seem to take some time, but after that the steep curve stands for a very fast development of the best practice. One explanation for this pattern could be the low absorptive capabilities at the beginning of the simulation runs. Because of this Schumpeter Mark I firms at first have problems absorbing external knowledge but, as shown in the graph, once the critical level of absorptive capacity is reached the best practice increases very fast. However, firms in Schumpeter Mark II invest in internal R\&D and in this setting the technological frontier develops at a greater pace.

In the evolution of the average knowledge for process innovations firms in Schumpeter Mark II

\footnotetext{
${ }^{9}$ The boxplot function used for presentation was programmed in Matlab by Ernest E. Rothman.
} 

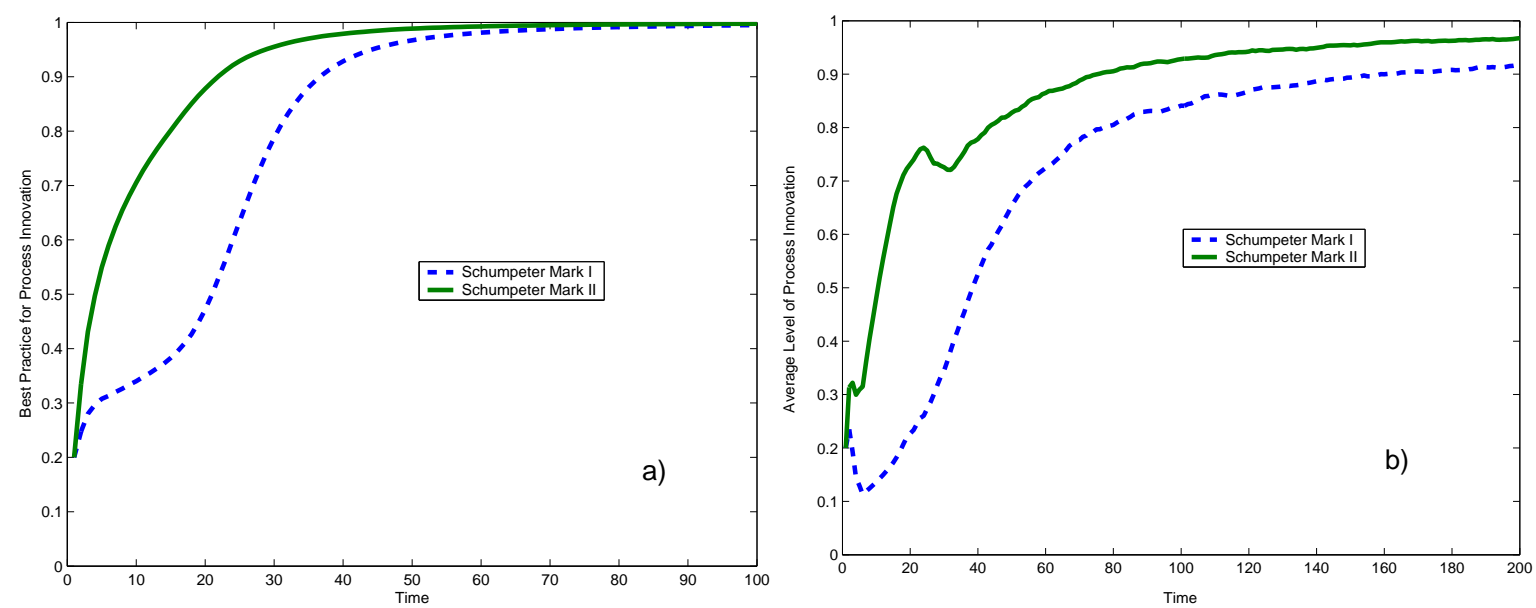

Figure 3: Process Innovations: Best Practice (a) and average Productivity (b).

show better outcomes. Two interesting effects can be seen in the right figure: First, at the beginning the average level of process innovations is reduced as more technologically lagging firms enter submarkets in Schumpeter Mark I. In Schumpeter Mark II this does not occur, possibly because high technological entry barriers prevent many firms from penetrating sub-markets. Second, after the first wave of new product variants there is a slowdown in the Schumpeter Mark II curve around period 30. This might result from the cumulative structure of knowledge for new technologies because at this time the first product variants are initialized at a lower level of knowledge. In the long run the lead of Schumpeter Mark II firms in terms of process innovations persists, but the difference is continuously reduced.

Summing up, the simulation study shows that the technological development is better in an industry that is characterized by Schumpeter Mark II conditions. The situation for process innovations is obvious because here the development of the best practice is faster and firms do on the average have lower production cost. In terms of product innovations there is a shift from early successful firms in Schumpeter Mark II to more innovative firms in Schumpeter Mark I in the long run. But taking the lower number of firms that innovate in Schumpeter Mark II into account, the technological development in terms of number of product innovations per firm could be interpreted as superior to the other scenario, too.

\subsection{Market and Industry Concentration}

In the model by Winter (1984) the outcome for the main industry characteristics is the following: the industry is less concentrated and less profitable in the Schumpeter Mark I regime and prices are similar in both scenarios. The interpretation of technological regimes in this paper partially reproduces these findings. First, it can be shown that the average profitability is indeed higher in Schumpeter Mark II. Second, in contrast to Winter (1984) prices appear not to be equal but lower in the Schumpeter Mark I scenario. ${ }^{10}$ And third, for aspects of concentration evidence is mixed.

In figure 4 two forms of concentration are demonstrated: the average concentration of quantities on markets (a) and the average concentration of the whole industry given by aggregated profits (b).

\footnotetext{
${ }^{10}$ Our result of lower prices corresponds to the lower market concentration in Schumpeter Mark I and the latter is also indicated by Winter (1984).
} 

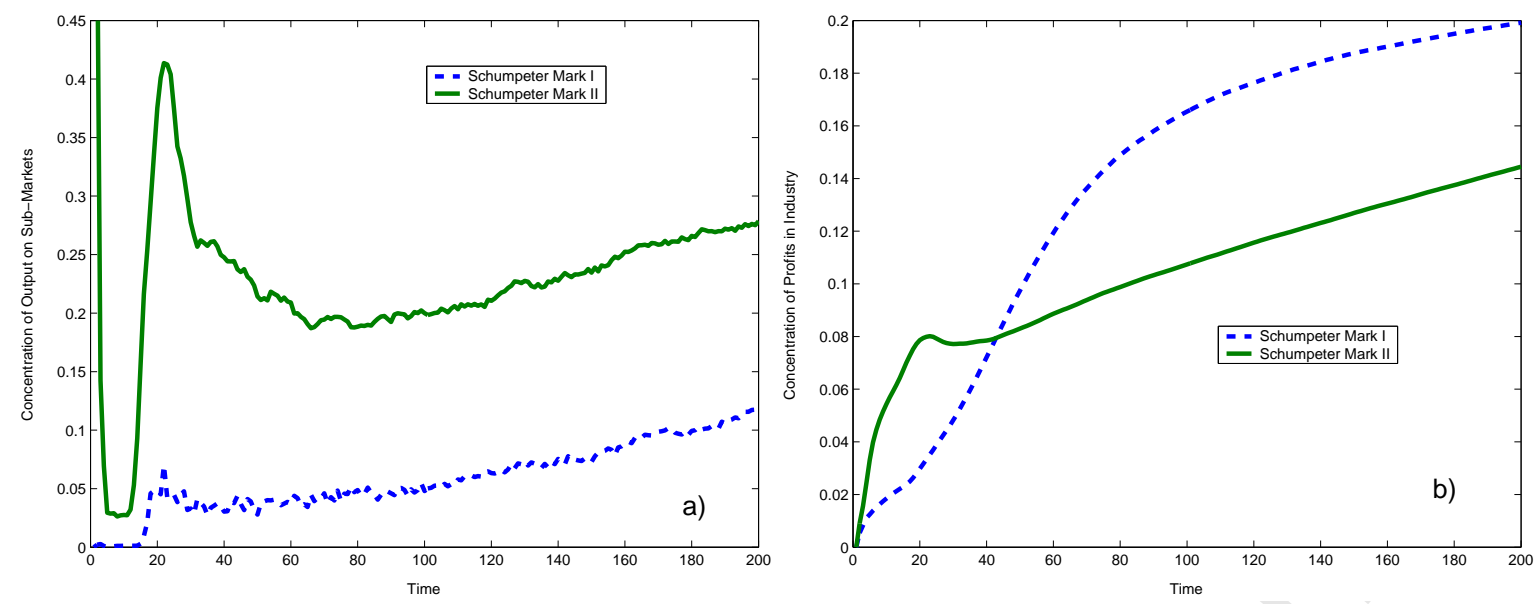

Figure 4: Market Concentration (a) and Industry Concentration (b).

Both variables are calculated as normalized Herfindahl indexes. ${ }^{11}$

It is interesting to see that in both technological regimes market concentration rapidly falls to low values at start and with the first introduction of new products market concentration jumps to a higher level. In Schumpeter Mark II the high technological entry barriers enable the innovating firm to stay as a monopolist on new markets. But because the average market concentration in Schumpeter Mark II is still much below 1, firms enter open markets despite the difficulties. The low technological entry barriers in Schumpeter Mark I lead to fast entries in new sub-markets so that the market concentration is much lower. This result was also obtained by Winter (1984). As the industry evolves more incremental product innovations reduce the demand for each product variant. The number of active firms on established sub-markets goes down because fewer firms can be profitable. Because of this market concentration is rising in both cases.

The industry concentration measures how equally the aggregated profits are distributed over all firms in the industry at a certain point of time. During the first periods firms in Schumpeter Mark II differ more. But after the first product innovations the curve for Schumpeter Mark I is much steeper, which leads to higher industry concentration in the longer run. The high value for Schumpeter Mark I is surprising because the structure of knowledge is less cumulative. The absorptive capacity could be an explanation for the strongly increasing difference in aggregated profits because firms with low absorptive capacity cannot use external learning opportunities and are therefore less profitable. Over time industry concentration increases in both cases. This means that previously successful firms become more successful showing a strong separation between technologically leading and technologically lagging companies. ${ }^{12}$ This effect is even stronger for firms in Schumpeter Mark I.

If we accept the view that the technological development of an industry stands for dynamic efficiency and the development of prices, profits and market concentration for static efficiency ${ }^{13}$, then the findings of the simulations could point at a trade-off between static and dynamic efficiency. Industries with conditions similar to Schumpeter Mark II may show more innovations and lower production costs but, on the other hand, this is associated with monopolistic tendencies in form of higher prices, higher

\footnotetext{
${ }^{11}$ Market concentration is given by $H=\left[\frac{\sum}{\left(\sum a_{i}\right)^{2}}-1 / n\right] \cdot \frac{1}{1-1 / n}$ with $a_{i}=x_{i, j, t}$, and analogously industry concentration with $a_{i}=\sum_{t} \Pi_{i, t}$.

${ }^{12}$ In the literature the effect is sometimes described as 'success breeds success' (e.g. Malerba and Orsenigo, 2000).

${ }^{13}$ Of course there is nothing to say about efficiency while comparing two economic examples. These terms are sometimes used in the literature to define the outcome or process of competition (see e.g. Blaug, 2001).
} 
profits and higher market concentration. It is important to add that in the long run the Schumpeter Mark I scenario shows more and more radical product innovations. High profits only lead to a better technological development when firms concentrate on internal research activities and, thus, high profits in Schumpeter Mark I would not provoke innovations to the same degree as firms are more focused on external learning.

\subsection{Firm Specialization and Learning}

The formulation of knowledge stocks which are located on a circular technological space allows a representation of the firms' technological portfolio. For every firm it is possible to analyze the height and location of the knowledge stocks. In this context it is feasible to measure firm specialization which takes into account the properties of knowledge. A specialized firm has high peaks which are located close to each other, and a not specialized (or diversified) firm has peaks which are equally high and uniformly distributed over the circular technological space. Both types of specialization are calculated with a normalized Herfindahl index, one for the height of knowledge and one for the location of knowledge. ${ }^{14}$ The closer the index is to 1 , the more specialized are the firms in average.
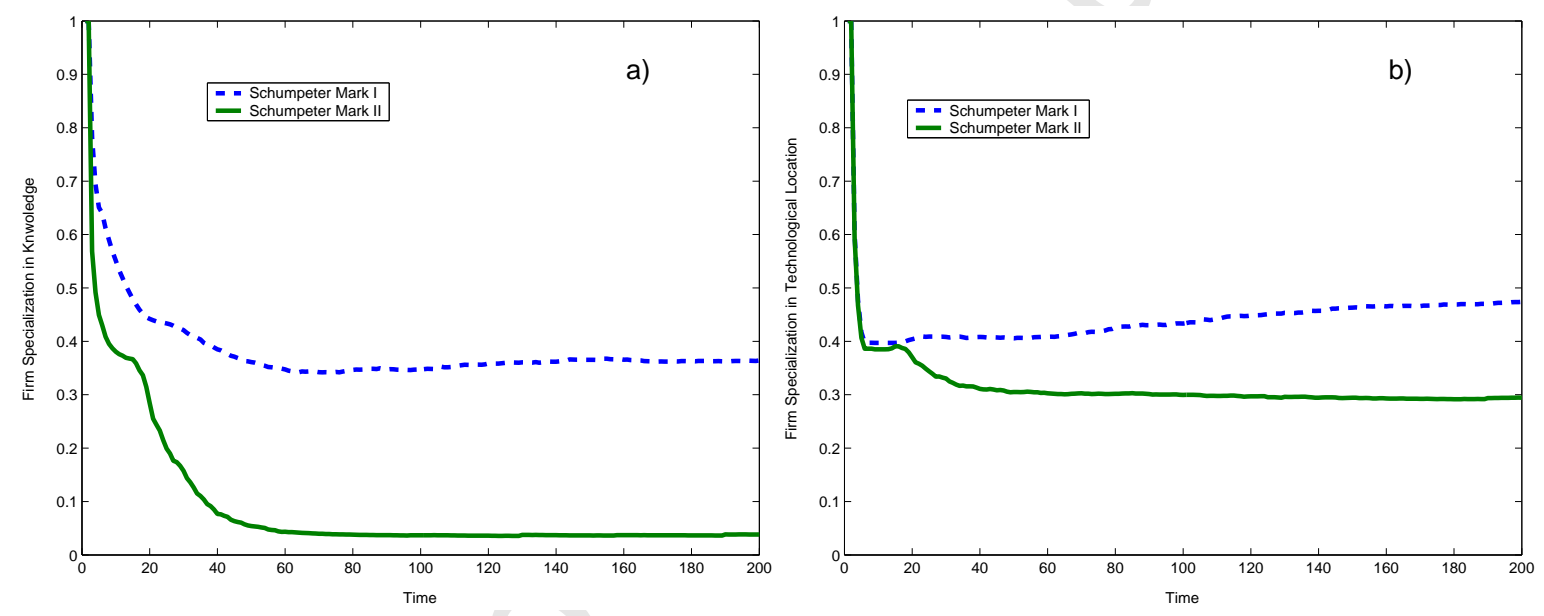

Figure 5: Firm Specialization in Height (a) and Location (b) of Knowledge.

Figure 5 shows the average values over all firms for both forms of specialization. All curves start at 1 for maximal specialization because each firm is initialized with knowledge in exactly one technology. In the first phase of the simulation firms gain knowledge in other technologies as they enter submarkets and invest in R\&D or learn. Again the introduction of first product innovations has a major influence on the curves leading to more diversified firms, in Schumpeter Mark II especially. Both graphs of Schumpeter Mark II seem to converge to a low level of specialization whereas the graphs for Schumpeter Mark I keep increasing as time goes by. The interpretation of the picture is obvious: firms in Schumpeter Mark I are on the average more specialized in terms of height as well as location of knowledge in the technology space.

The result of higher firm specialization in Schumpeter Mark I is rather surprising and tests with different parameters (e.g. number of firms or forms of knowledge build-up in the public institution) suggest that this result is quite robust. Knowledge and technological progress in Schumpeter Mark II

\footnotetext{
${ }^{14}$ Specialization in height is given by $H=\left[\frac{\sum a_{j}^{2}}{\left(\sum a_{j}\right)^{2}}-1 / m_{t}\right] \cdot \frac{1}{1-1 / m_{t}}$ with $a_{j}=R D_{i, j, t}^{\text {proc }}$ and specialization in location with $a_{j}=d_{j, j+1, t}^{t e c h}$.
} 
are strongly cumulative at firm level. Hence, one would expect highly specialized firms because knowledge is best transferred through internal spillover with similar peaks located close to each another. In contrast to this the sources of knowledge in Schumpeter Mark I are very diversified resulting from the external institution and imitation from competitors. Firms do have very broad opportunities to learn and one would expect more diversified firms in Schumpeter Mark I.

In order to explain this finding three possible arguments could be of relevance. First, it could be the case that the scale of learning and R\&D projects is much smaller in Schumpeter Mark I and so firms can only develop knowledge in and around their starting point. Second, investments in R\&D could lead to more diversified firms and external learning could generate more specialized firms under the described circumstances. And third, the scenario of 'creative destruction' could have significant influence on the technology space resulting in more specialized firms. These arguments should be discussed in detail.

$\square$ Investments in R\&D $\square$ External and Internal Knowledge Spillovers $\square$ Knowledge Spillovers from Public Institution
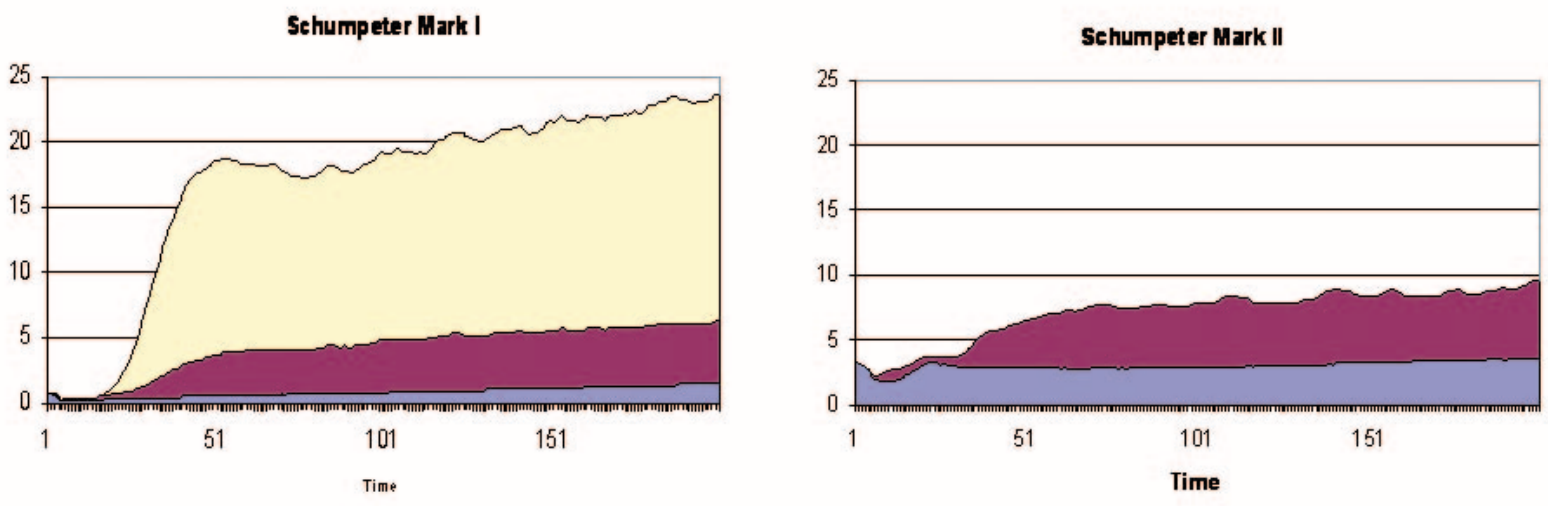

Figure 6: Sum of Learning from different Sources.

For the generation of knowledge firms use investments in R\&D, internal learning, imitation from competitors and learning from the public institution as described in the model in section 3 . All elements are understood as perfect substitutes to create knowledge. Figure 6 presents the sum of investments in $R \& D$ and all types of knowledge spillover for process innovations to see if the scale has an impact on the high level of firm specialization in Schumpeter Mark I. In Schumpeter Mark II only 5 instead of 10 firms exist in the industry. The graphs show that the sum of R\&D and knowledge spillover in Schumpeter Mark I is (after an initial phase) at least twice as high. Hence, a firm in Schumpeter Mark I benefits from R\&D and learning on the average at least as much as a firm in Schumpeter Mark II. Additionally this is supported by evidence that the level of absorptive capacity evolves equally in both scenarios. Therefore, the amount of learning and a possible shortfall of absorptive capacity cannot be the reason for high specialization of firms in Schumpeter Mark I.

The second argument debates not the scale but the structure of the acquired knowledge. Firms in Schumpeter Mark II can create knowledge very fast in selected technological areas because investments in R\&D do not rely on the existing level of knowledge. On the contrary, knowledge spillovers depend on the gap between the specific knowledge stocks. In Schumpeter Mark I firms may have less influence on the technological areas they want to improve. Instead they rely more on the external technological development. Because of this, it could be argued that R\&D activities are more focused and guided. 
Firms in Schumpeter Mark II have more freedom to change their temporary technological emphasis with high investments in R\&D. Firms can enter profitable sub-markets having in mind that high investments in process innovations allow a fast catch-up to the incumbents independent of the current knowledge in this technology. As a second option higher profits in Schumpeter Mark II lead to higher investments in product innovations and more successful product innovations (per firm) can be conducted next to profitable markets. More product innovations in technologies which have so far not been known to the firm cause more diversified firms in Schumpeter Mark II, too. Although learning possibilities in Schumpeter Mark I are very broad, firms appear to absorb only technologically close knowledge and this generates much more specialized firms. Indeed, the structural difference between more guided investments in $\mathrm{R} \& \mathrm{D}$ and less controlled external learning may be a reason for more diversified firms in Schumpeter Mark II.

The technological regime of Schumpeter Mark I was characterized as 'creative destruction'. This view can be supported by figure 2, which shows that the number of radical product innovations are much higher in Schumpeter Mark I. Every radical product innovation distorts the technological space because it separates two previous technologies and the technological circle is expanded. The technological distances between technologies increase and it becomes more difficult to learn in distant technological areas. Firms in a rapidly changing technological space caused by more radical product innovations have difficulties to keep a diversified technological portfolio. Therefore, major changes in the technology space could be another explanation for the higher firm specialization in Schumpeter Mark I.

\section{Conclusions}

The aim of this paper is to address the two views of Schumpeter on competition. An agent-based simulation model is formulated which highlights the role of learning and knowledge spillovers in an innovative industry. Results of the simulation study show persistent structural differences between Schumpeter Mark I and Schumpeter Mark II conditions.

Like all (simulation) models this model is limited due to the chosen functional form and the setting of parameters. This paper compares two scenarios in the way that certain elements, which define a technological regime, are varied whereas other parameters stay constant. This setup enables the identification of major differences independent of the constant parameters. The described technological regimes are only stylized examples but they indicates some interesting findings, which can be divided into two parts. The first group of results are connected to earlier work on technological regimes whereas the paper also provides new insights which, at least to the author's opinion, were not demonstrated previously in other simulation or equilibrium models.

The fact that this new formulated model of an innovative industry replicates the major results of Winter (1984) can be seen as a support for the reliability of the earlier findings: The technological development in terms of process and product innovations is better in an industry that is characterized by Schumpeter Mark II conditions, but the improved technological development is connected with higher prices and profits. In both scenarios market and industry concentration rises over time, showing a strong separation between successful firms and those lagging behind in technological terms. Thus, we provide an example of how insights from simulation models can be replicated, and we are convinced that the model-to-model analysis helps to deepen the understanding of both models.

Further, our interpretation of learning enables the formulation of new arguments to the debate on technological regimes which go beyond pure replication. The technological development could be 
analyzed taking into account process as well as product innovations, and the study of main industry characteristics shows new insights concerning the competitiveness of firms over time. It was demonstrated that internal and external learning influences the outcome for radical product innovations and specialization of firms. In general, firms in the Schumpeter Mark II regime can be active in technological terms due to their own high investments in product and process innovations, whereas firms in the Schumpeter Mark I regime remain passive as they depend on the external technological development. In connection with a rapidly changing technology space this emerges in more diversified firms in Schumpeter Mark II. This new result was not assessed in earlier works on technological regimes and can be taken as a proposition to be tested with other models and empirical studies of the reality.

Taken together the findings indicate that there is no ideal technological regime, because both types have their own merits which contribute to different political goals. A better technological development of the industry was in this setting connected with more market power by the firms. But it was argued that competition between markets may substitute for competition on markets. Politicians should also realize that broad and wide learning conditions from public institutions do not support all firms, especially not those with a low absorptive capacity. In fact external learning has proven to be more selective than focusing on $\mathrm{R} \& \mathrm{D}$ investments.

One critique of this paper aimed at the assumption of involuntary knowledge spillovers without the necessity to connect partners for example by cooperation and networking. The question emerges whether technological regimes have to consider a cooperation dimension. As mentioned in section 2 the transfer of knowledge can already be connected to the traditional conditions of the technological regimes. Especially, the degree of tacitness of knowledge as part of the knowledge base and aspects of proximity are important for the transfer of knowledge. Apart from technological proximity the notion of geographical proximity is debated in this context, whereas the interpretation of geographical proximity incorporates elements of temporary proximity and professional meetings. Further, the willingness to cooperate can be seen as a strategic option of the firms. Therefore, cooperation and networking is more a question of firm innovation strategy than of technological environment under which firms operate. Nevertheless, the discussion of different cooperation strategies is important and should be on the agenda for future research. In particular the methodology of agent-based simulation seems to be very suitable in this context as it allows to model heterogenous firm behavior in a complex technological surrounding. The same holds for an evaluation of different policy measures which can be tested with this method such as a computational laboratory.

\section{References}

Aghion, P., Bloom, N., Blundell, R., Griffith, R., Howitt, P., 2005. Competition and innovation: An inverted-U relationship. Quarterly Journal of Economics 120, 701-728.

Audretsch, D. B., 1991. New-firm survival and the technological regime. Review of Economics and Statistics $73,441-450$.

Blaug, M., 2001. Is competition such a good thing? Static efficiency versus dynamic efficiency. Review of Industrial Organization 19, 37-48.

Boschma, R.A., 2005. Proximity and innovation: a critical assessment. Regional Studies 39, 61-74.

Breschi, S., Malerba, F., Orsenigo, L., 2000. Technological regimes and Schumpeterian patterns of innovation. Economic Journal 110, 388-410. 
Burton, R.M., 2003. Computational laboratories for organization science: Questions, validity and docking. Computational and Mathematical Organization Theory 9, 91-108.

Cohen, W., 1995. Empirical studies of innovative activity. In: Stoneman, P. (Ed.). Handbook of the Economics of Innovation and Technological Change. Blackwell, Oxford, 182-264.

Dawid, H., 2006. Agent-based models of innovation and technological change. In: Tesfatsion, L., Judd, K., Intriligator, M. D., Arrow, K. (Eds.). Handbook of Computational Economics, Vol. 2: Agent-based Computational Economics, North-Holland, 1235-1272.

Dawid, H., Reimann, M., 2005. Evaluating market attractiveness: Individual incentives vs. industrial profitability. Computational Economics 24, 321-355.

Dawid, H., Reimann, M., 2010. Diversification: A road to inefficiency in product innovations?. Journal of Evolutionary Economics, forthcoming.

Dosi, G., Marsili, O., Orsenigo, L., Salvatore, R., 1995. Learning, market selection and the evolution of industrial structures. Small Business Economics 7, 411-436.

Garavaglia, C., Malerba, F., Orsenigo, L., 2006. Entry, market structure and innovation in a "Historyfriendly" model of the evolution of the pharmaceutical industry. In: Mazzucato, M. Dosi, G. (Eds.). Knowledge Accumulation and Industry Evolution: The Case of Pharma-Biotech. Cambridge University Press, Cambridge, 234-265.

Hales, D., Rouchier, J., Edmonds, B., 2003. Model-to-model analysis. Journal of Artificial Societies and Social Simulation 6:4, 5 .

Hamermesh, D. S., 2007. Viewpoint: Replication in economics. Canadian Journal of Economics 40, 715-733

Kamien, M. I., Schwartz, N. L., 1982. Market Structure and Innovation. Cambridge University Press, Cambridge.

Llerena, P., Oltra, V., 2002. Diversity of innovative strategy as a source of technological performance. Structural Change and Economic Dynamics 13, 179-201.

Malerba, F., Orsenigo, L., 1996. Schumpeterian patterns of innovation are technology-specific. Research Policy 25, 451-478.

Malerba, F., Orsenigo, L., 2000. Knowledge, innovation activities and industrial evolution. Industrial and Corporate Change 9, 289-313.

Marsili, O., 2001. The Anatomy and Evolution of Industries: Technological Change and Industrial Dynamics. Edward Elgar, Cheltenham.

Marsili, O., Verspagen, B., 2002. Technology and the dynamics of industrial structures: An empirical mapping of Dutch manufacturing. Industrial and Corporate Change 11, 791-815.

Nelson, R.R., Winter, S.G., 1982. An Evolutionary Theory of Economic Change. Harvard University Press, Cambridge, Mass. and London.

Pavitt, K., 1984. Sectoral patterns of technical change: Towards a taxonomy and a theory. Research Policy 13, 343-373. 
Pavitt, K., Robson, M., Townsend, J., 1989. Technological accumulation, diversification and organisation in UK companies, 1945-1983. Management Science 35, 81-99.

Schumpeter, J. A., 1912. Theorie der wirtschaftlichen Entwicklung. Dunckner \& Humblot, Leipzig.

Schumpeter, J. A., 1942. Capitalism, Socialism, and Democracy. Harper and Row, New York.

Tesfatsion, L., 2006. Agent-based computational economics: A constructive approach to economic theory. In: Tesfatsion, L., Judd, K., Intriligator, M. D., Arrow, K. (Eds.). Handbook of Computational Economics. Vol. 2: Agent-based Computational Economics, North-Holland, 831-880.

Wersching, K., 2007. Agglomeration in an innovative and differentiated industry with heterogeneous knowledge spillovers. Journal of Economic Interaction and Coordination 2, 1-25.

Windrum, P., Fagiolo, G., Moneta, A., 2007. Empirical validation of agent-based models: Alternatives and prospects. Journal of Artificial Societies and Social Simulation 10:2, 8.

Winter, S. G., 1984. Schumpeterian competition in alternative technological regimes. Journal of Economic Behavior and Organization 5, 287-320.

Wuyts, S., Colombo, M. G., Dutta, S., Nooteboom, B., 2005. Empirical tests of optimal cognitive distance. Journal of Economic Behaviour and Organization 58, 277-302.

\section{Appendix}

\section{Appendix A: Parameter Settings}

\begin{tabular}{cc|cc} 
Parameter & Value & Parameter & Value \\
\hline \hline$T$ & 200 & Runs & 100 \\
$R D^{0}$ & 0.2 & $d_{0}^{\text {tech }}$ & 2 \\
$B_{m}$ & 3 & $m_{0}$ & 5 \\
$c_{j}^{\text {min }}$ & 0.3 & $c_{j}^{i n i}$ & 0.5 \\
$S^{0}$ & 10 & $F_{i}$ & {$[0.2,0.4]$} \\
$\alpha_{i}$ & {$[3,4]$} & $\beta_{i}$ & {$[0.75,0.85]$} \\
$\alpha^{\text {ext }}$ & {$[3,4]$} & $\beta^{\text {ext }}$ & {$[0.75,0.85]$} \\
$\kappa_{i}$ & {$[0,1]$} & $\delta_{i}$ & {$[0,1]$} \\
$q_{i}^{\text {prod }}$ & {$[0.24,0.32]$} & $q_{i}^{\text {proc }}$ & {$[0.08,0.14]$} \\
\hline \multicolumn{2}{c}{}
\end{tabular}

Table 2: Parameter settings.

If the parameters are indicated as an interval, the values for the parameters were chosen uniformly distributed in the given range for every simulation run.

\section{Appendix B: Statistical Tests}

In order to present statistical analysis a two-sample Wilcoxon rank sum test is used where this test does not assume that the observations come from normal distributions. The alternative hypothesis is formulated and the results of 100 simulation runs are tested. With the exception of test 2 the null hypothesis can be rejected at a confidence level greater than $99 \%$ (greater than $90 \%$ in test 2). 
1. Number of Product Innovations at $T=80$ :

H0: Schumpeter Mark I $\geq$ Schumpeter Mark II

H1: Schumpeter Mark I < Schumpeter Mark II

Results: $\mathrm{Z}=-3.2997$, $\mathrm{p}$-value $=0.0005$

2. Number of Product Innovations at $T=160$ :

H0: Schumpeter Mark I S Schumpeter Mark II

H1: Schumpeter Mark I > Schumpeter Mark II

Results: $\mathrm{Z}=1.3426, \mathrm{p}$-value $=0.0897$

3. Number of radical Product Innovations over the simulated periods:

HO: Schumpeter Mark I $\leq$ Schumpeter Mark II

H1: Schumpeter Mark I > Schumpeter Mark II

Results: $\mathrm{Z}=8.0736$, p-value $<0.0001$

4. Best Practice for Process Innovation at $T=50$ :

HO: Schumpeter Mark I $\geq$ Schumpeter Mark II

H1: Schumpeter Mark I < Schumpeter Mark II

Results: $\mathrm{Z}=-9.8139, \mathrm{p}$-value $<0.0001$

5. Average Level of Process Innovations at $T=200$ :

H0: Schumpeter Mark I $\geq$ Schumpeter Mark II

H1: Schumpeter Mark I < Schumpeter Mark II

Results: $\mathrm{Z}=-10.2512$, p-value $<0.0001$

6. Average Market Concentration at $T=200$ :

H0: Schumpeter Mark I $\geq$ Schumpeter Mark II

H1: Schumpeter Mark I < Schumpeter Mark II

Results: $\mathrm{Z}=-7.1445$, p-value $<0.0001$

7. Industry Concentration at $T=200$ :

H0: Schumpeter Mark I S Schumpeter Mark II

H1: Schumpeter Mark I> Schumpeter Mark II

Results: $\mathrm{Z}=5.6784, \mathrm{p}$-value $<0.0001$

8. Average Firm Specialization in Knowledge at $T=200$ :

HO: Schumpeter Mark I $\leq$ Schumpeter Mark II

H1: Schumpeter Mark I > Schumpeter Mark II

Results: $\mathrm{Z}=12.0777$, p-value $<0.0001$

9. Average Firm Specialization in Location at $T=200$ :

H0: Schumpeter Mark I $\leq$ Schumpeter Mark II

H1: Schumpeter Mark I > Schumpeter Mark II

Results: $\mathrm{Z}=9.1762$, p-value $<0.0001$ 